\title{
Letter to editor: Covid-19 and dealing with it-lessons learned in Iran
}

\author{
Pooneh Maziar ${ }^{1}$, Sajjad Razavi*2,3 (D), Leila Hosseini Ghavamabad ${ }^{4}$
}

Received: 3 Jun 2020

Published: 31 Aug 2020

Conflicts of Interest: None declared

Funding: None

*This work has been published under CC BY-NC-SA 1.0 license.

Copyright $\subseteq$ Iran University of Medical Sciences

Cite this article as: Maziar P, Razavi S, Hosseini Ghavamabad L. Letter to editor: Covid-19 and Dealing with It-Lessons Learned in Iran. Med J Islam Repub Iran. 2020 (31 Aug);34:110. https://doi.org/10.47176/mjiri.34.110

\section{Dear Editor}

We have read with great interest the Editorial in the first issue of the 34th volume of the Medical Journal of the Islamic Republic of Iran, entitled "Lessons to be learned from the prevalence of Covid-19 in Iran" (1).

We would like to add other measures taken by MOHME (Ministry of Health \& Medical Education) since the beginning of the official announcement of the diagnosis of Covid-19 in Iran to that editorial.

According to the country, a quarter of the world's population lives in Southeast Asia, which is at high risk for the spread of common diseases and are highly vulnerable to emerging diseases and the re-emergence of epidemics, such as seasonal flu. In addition, due to the frequent occurrence of events, such as floods, landslides, and adverse consequences of climate change and limited capacity of systems to respond to the spread of new pathogens with unknown etiology or intentional biological events, reevaluating strategy and planning is of paramount importance. Also,

Corresponding author: Dr Sajjad Razavi, s.razavi@sbmu.ac.ir

1. Ministry of Health and Medical Education, Tehran, Iran

2. Mofid Children Hospital, Tehran, Iran

3. High Council of Health Insurance, Ministry of Health and Medical Education, Tehran, Iran

4. Deputy General Director of Health Technology Assessment, Standards \& Tariffs Office, Ministry of Health and Medical Education, Tehran, Iran strengthening emergency preparedness to ensure timely and effective response to biological threats is equally important (2).

The world is not ready to respond to the spread of severe flu or other global health emergencies (3).

Studies show countries do not make good use of what they have learned from the experiences of other countries (4).

Therefore, the publication of lessons learned by countries and measures taken to combat pandemics can be more effective in preparation and accountability. This letter refers to the most important measures taken against Covid-19 in Iran. After the official announcement of the diagnosis of the first cases of the disease on February 20, 2020, the Corona National Headquarters was immediately formed by the order of the President. Subsequently, other measures were gradually taken to respond to and control the disease.

The establishment of 16-hour and 24-hour health service centers was able to identify a large number of patients in

$\uparrow$ What is "already known" in this topic:

Extensive efforts have been made around the world to manage Covid-19. Each country has taken steps based on previous epidemic experiences of infectious diseases, health protocols, the country's socioeconomic status, and macropolicies. The purpose of this article was to express the most important actions of the Ministry of Health of Iran in response to Covid-19 disease.

$\rightarrow$ What this article adds:

The Ministry of Health of Iran has taken important steps to combat Covid-19 disease, but for better preparation and response, other measures must be taken and expanded, including the development of a national preparedness plan for pandemics, risk assessment, communication risk, and staff training, preparation and simulation maneuvers, investment, information management and more coordinations. 
the first level of service in the form of face-to-face service and telephone contact with patients using health care providers and volunteers, and hospitals admission reduced with patient guidance for home care.

The most important measures taken were as follow: the potential support from outside the body of MOHME, including the Armed Forces, the Social Security Organization, the Red Crescent Society, donors and nongovernmental organizations, the Medical System Organization, and mobilization of the medical community.

An epidemiology committee was established for analyzing and monitoring the disease situation in the country and drawing up possible scenarios.

A 4030 response system with the participation of the Medical System Organization was set up for counseling and responding to the general public.

A scientific committee in the deputy for curative affairs with the presence of experts in MOHME and universities formed and developed more than 100 guidelines and directives in the fields of environmental and occupational health, diagnosis and treatment protocols for special groups nutritional support, dental services, elective surgery, protection of health care personnel, telemedicine, implementation of support regulations (eg, limitation of office and surgery centers, the abolition of medical leave, the ban on visits).

Educational needs assessment and holding scientific webinars to transfer successful experiences and review treatment measures and problem-solving were other measures.

Regular video conferences with the media and participating in various programs in radio and television are held for effective communication and information.

Moreover, a documentation committee was formed to collect all actions taken for use in other critical situations.

The fair distribution of personal protective equipment (PPE) was managed in the country's hospitals. Guidelines were developed to provide material, social, and psychological support to patients and their families. Manpower, especially infectious disease specialists, provided and dispatched to all universities in the country.

The country's laboratory network expanded and the electronic information registration system strengthened and the laboratories and medical personnel were trained.

The insurance coverage, preparation of essential medicines, financial protection, and distribution of health packages for support patients with COVID-19 and specific patients were accomplished.

The other important activity was including deceased medical personnel as martyrs of service in appreciation of their enduring efforts have been among the other measures.

Fortunately, because of the Health Transformation Plan outcomes and the increase in inpatient beds, particularly special beds, there was no significant shortage in the number of beds.

According to a report by the World Health Organization (WHO) examining global measures to combat COVID-19, the lessons to be learned for future crises are to adopt clear policies for early warning of global health emergencies and to take precautions, including screening citizens of highrisk countries, quarantining dangerous areas as soon as the health threat is identified, transparency and free access to all information to prevent the spread of misinformation, creating a framework for the spread of the disease to understand the severity of the threat, and to invest more in effective treatment (5).

In addition to the issues mentioned in the Omidi et al's editorial about the weaknesses of the Ministry of Health's programs (1), other measures that need to be taken to improve the response and control of COVID-19 in Iran include developing a national preparedness program to combat pandemics, risk assessment, risk communication, personnel training, preparation and simulation maneuvers, investment, management information, increasing the coordination of the health system and other departments, and determining the responsibilities and positions of all officials.

\section{Conflict of Interests}

The authors declare that they have no competing interests.

\section{References}

1. Omidi M, Maher A, Etesaminia S. Lessons to be learned from the prevalence of Covid-19 in Iran. Med J Islam Repub Iran. 2020;34(1):398-399.

2. Wijesinghe PR, Ofrin RH, Bhola AK, Inbanathan FY, Bezbaruah S. Pandemic influenza preparedness in the WHO South-East Asia Region: a model for planning regional preparedness for other priority highthreat pathogens. WHO South-East Asia J Public Health. 2020;9(1):43-

3. World Health Organization. Global influenza strategy 2019-2030. https://appswhoint/iris/handle/10665/311184. 2019.

4. World Health Organization. Key changes to pandemic plans by Member States of the WHO European Region based on lessons learnt from the 2009 pandemic. Europe Retrieved from http://www ecdc europaeu/en/publications/publications/1203-merjoint_who_euro_pip\% 20workshops\% 20summary pdf. 2012.

5. Sohrabi C, Alsafi Z, O'Neill N, Khan M, Kerwan A, Al-Jabir A, et al. World Health Organization declares global emergency: A review of the 2019 novel coronavirus (COVID-19). Int J Surg. 2020. 